\title{
Malaria during pregnancy and foetal haematological status in Blantyre, Malawi
}

\author{
Elizabeth T Abrams ${ }^{1}$, Jesse J Kwiek2 ${ }^{2}$, Victor Mwapasa ${ }^{3}$, \\ Deborah D Kamwendo ${ }^{4}$, Eyob Tadesse 5 , Valentino M Lema ${ }^{5}$, \\ Malcolm E Molyneux ${ }^{6,7}$, Stephen J Rogerson 7,8 and Steven R Meshnick*2
}

Address: ${ }^{1}$ Department of Humanities and Social Sciences, California Institute of Technology, Pasadena, California, USA, ${ }^{2}$ Department of Epidemiology, University of North Carolina, Chapel Hill, North Carolina, USA, ${ }^{3}$ Department of Community Health, University College of Medicine, University of Malawi, Blantyre, Malawi, ${ }^{4} \mathrm{UNC}$ Project, Lilongwe, Malawi, ${ }^{5}$ Department of Obstetrics and Gynaecology, College of Medicine, University of Malawi, Blantyre, Malawi, ${ }^{6}$ School of Tropical Medicine, University of Liverpool, Liverpool, UK, ${ }^{7}$ Malawi-LiverpoolWellcome Trust Clinical Research Programme, College of Medicine, University of Malawi, Blantyre, Malawi and ${ }^{8}$ Department of Medicine, University of Melbourne, Royal Melbourne Hospital, Parkville, Australia

Email: Elizabeth T Abrams - eabrams@hss.caltech.edu; Jesse J Kwiek - kwiek@unc.edu; Victor Mwapasa - vmwapasa@medcol.mw; Deborah D Kamwendo - dkamwendo@unclilongwe.org.mw; Eyob Tadesse - etnigussie@yahoo.com; Valentino M Lema - vmlema@yahoo.com; Malcolm E Molyneux - mmolyneux@mlw.medcol.mw; Stephen J Rogerson - sroger@unimelb.edu.au;

Steven R Meshnick* - meshnick@email.unc.edu

* Corresponding author

Published: 25 August 2005

Malaria Journal 2005, 4:39 doi:10.1 186/1475-2875-4-39

This article is available from: http://www.malariajournal.com/content/4/I/39

(C) 2005 Abrams et al; licensee BioMed Central Ltd.

This is an Open Access article distributed under the terms of the Creative Commons Attribution License (http://creativecommons.org/licenses/by/2.0), which permits unrestricted use, distribution, and reproduction in any medium, provided the original work is properly cited.
Received: 07 April 2005

Accepted: 25 August 2005

\begin{abstract}
Background: Although maternal anaemia often stems from malaria infection during pregnancy, its effects on foetal haemoglobin levels are not straightforward. Lower-than-expected cord haemoglobin values in malarious versus non-malarious regions were noted by one review, which hypothesized they resulted from foetal immune activation to maternal malaria. This study addressed this idea by examining cord haemoglobin levels in relation to maternal malaria, anaemia, and markers of foetal immune activation.

Methods: Cord haemoglobin levels were examined in 32 malaria-infected and 58 uninfected women in Blantyre, Malawi, in relation to maternal haemoglobin levels, malaria status, and markers of foetal haematological status, hypoxia, and inflammation, including TNF- $\alpha$, TGF- $\beta$, and ferritin. All women were HIV-negative.

Results: Although malaria was associated with a reduction in maternal haemoglobin ( $10.8 \mathrm{~g} / \mathrm{dL}$ vs. $12.1 \mathrm{~g} /$ $\mathrm{dL}, \mathrm{P}<0.00 \mathrm{I})$, no reduction in cord haemoglobin and no significant relationship between maternal and cord haemoglobin levels were found. Cord blood markers of haematological and hypoxic statuses did not differ between malaria-infected and uninfected women. Maternal malaria was associated with decreased TGF- $\beta$ and increased cord ferritin, the latter of which was positively correlated with parasitaemia $(r=$ $0.474, p=0.009$ ). Increased cord ferritin was associated with significantly decreased birth weight and gestational length, although maternal and cord haemoglobin levels and malaria status had no effect on birth outcome.

Conclusion: In this population, cord haemoglobin levels were protected from the effect of maternal malaria. However, decreased TGF- $\beta$ and elevated ferritin levels in cord blood suggest foetal immune activation to maternal malaria, which may help explain poor birth outcomes.
\end{abstract}




\section{Background}

Malaria affects more than three million pregnant women per year in developing countries, where it commonly causes poor birth outcomes and maternal anaemia [1-3]. Brabin [4] suggested that foetal anaemia also resulted from maternal malaria during pregnancy. In developed countries, anaemia in newborns is rare, regardless of maternal status, and normal neonatal haemoglobin levels in these populations are higher than adult levels [e.g. [5]] In addition, there appears to be little relationship between maternal and umbilical cord haemoglobin levels, even when mothers are anaemic [e.g., [5,6]]. For example, a study of pregnant Turkish women found no significant difference in mean cord haemoglobin levels of neonates of anaemic $(\mathrm{Hb}<10 \mathrm{~g} / \mathrm{dL})$ mothers (mean \pm SEM: 16.11 $\pm 0.39 \mathrm{~g} / \mathrm{dL}$ ) compared to those of non-anaemic ( $\mathrm{Hb} \geq 12$ $\mathrm{g} / \mathrm{dL}$ ) mothers (mean $\pm \mathrm{SEM}: 16.57 \pm 1.35 \mathrm{~g} / \mathrm{dL}$ ) [5]. In developing countries, the situation is more complex. In non-malarious areas, babies of mothers with iron-deficient anaemia have both relatively similar [e.g., [7]] and higher [e.g., $[8,9]]$ cord haemoglobin levels than those reported for developed countries. In contrast, cord haemoglobin levels in malarious areas have been characterized by Brabin [4] as lower-than-expected, hypothesized to result from foetal immune activation to maternal malarial antigens.

In non-malarious regions, maternal anaemia may stem chiefly from iron deficiency; higher cord haemoglobin levels may thus reflect a response to foetal hypoxia caused by decreased placental oxygen transport [10]. In malarious regions, however, malaria infections during pregnancy present a second source of maternal anaemia by increasing red blood cell destruction and decreasing erythropoiesis $[3,11,12]$. These effects may be mediated in part by elevations in proinflammatory cytokines like TNF- $\alpha$, which are associated with maternal anaemia in malariainfected pregnancies $[13,14]$. Although malaria elevates placental proinflammatory cytokine production during pregnancy [14-16], it has not been reported to affect cord levels [15]. However, maternal malaria may immunologically prime the foetus, as several researchers have reported that foetal explants produce proinflammatory cytokines upon exposure to maternal malarial antigens $[17,18]$.

To further address the hypothesis that cord haemoglobin levels in malarious areas are lower than expected due to foetal immune activation to maternal malaria, cord haemoglobin levels were examined in this study in malariainfected and uninfected women in relation to maternal malaria status and haemoglobin levels and markers of foetal haematological, inflammatory, and hypoxic status. In specific, chronic foetal hypoxia was assessed via levels of erythropoietin (Epo) [19], a hormone responsible for red blood cell production, and corticotrophin releasing hormone $(\mathrm{CRH})$ and cortisol, two hormones that have been hypothesized to mediate the effects of anaemiarelated hypoxia on poor birth outcomes [20]. Tumor necrosis factor alpha (TNF- $\alpha$ ), a pro-inflammatory cytokine, transforming growth factor beta (TGF- $\beta$ ), an anti-inflammatory cytokine, and C-reactive protein (CRP), an acute shock protein, were assayed as markers of inflammatory status. Haematological status was assessed via umbilical cord levels of haemoglobin ( $\mathrm{Hb}$ ) and soluble transferrin receptor (sTfR). Levels of ferritin, an iron storage protein that is an acute phase reactant in the presence of infection, were also assayed.

As markers of interest were measured both in maternal peripheral and umbilical cord blood, one critical issue is whether the cord measures truly reflect foetal production rather than placental transfer of maternally produced factors. Human data addressing this topic is limited, given the invasive and/or complex nature of the required studies. In general, studies suggest that most substances can cross the placenta, with the rate dependent on molecular weight, such that those with larger molecular weights cross slowly and those with molecular weights under 500 daltons quite rapidly [21]. Erythropoietin, a protein with a large molecular weight, is undetectable on the placental side opposite its origin [22], and it is likely that high molecular weight sequesters other large molecules like ferritin [23] on the side of the placenta on which they were produced. A placental perfusion study of inflammatory cytokine transfer suggested that TNF- $\alpha$, a cytokine measured in this study, does not readily cross from the maternal to the foetal side of the placenta, although IL-6, which was not assayed in this study, appears to cross the placenta bidirectionally [24]. CRP is also unlikely to cross the placenta [25]. Cortisol may cross the placenta in its active form, but foetal exposure to maternal cortisol is normally limited by the conversion of cortisol to cortisone, its inactive metabolite, by placental $11 \beta$-hydroxysteroid dehydrogenase [26].

\section{Methods Subjects}

Ninety pregnant women pre-labor or in the latent phase of labor attending the Labour Ward, Queen Elizabeth Central Hospital, Blantyre, Malawi, were recruited from February to October 2002 as part of a prospective cohort study investigating the impact of maternal malaria on HIV vertical transmission [27]. All women with positive peripheral malaria blood smears in the larger study were enrolled, along with the next two sequential uninfected women. Women were excluded from this study if they had HIV, preeclampsia, or multiple gestations. 
Maternal socio-economic (marital status, educational level, maternal and paternal occupations, and house construction), health (antenatal clinic attendance and iron tablets usage) and anthropometric (height, weight, and mid-upper arm circumference (MUAC)) data were collected. Neonatal anthropometrics (head, abdominal, and arm circumferences, recumbent length, and weight) were evaluated within the first 24 hours after birth. Gestational age was determined by the New Ballard Score [28].

\section{Sampling procedure}

Maternal peripheral blood samples were taken at recruitment, and cord and placental samples were collected at delivery. Thick blood films were prepared from these samples for malaria microscopy. Placental blood was collected into EDTA by incising the cleaned maternal surface of the placenta and aspirating blood welling from the incision with a sterile pipette. Samples were separated within one hour, and plasma was stored at $-70^{\circ} \mathrm{C}$. Placental biopsies from a pericentric area (approximately $1 \mathrm{~cm}$ from the cord on the maternal side) were placed into $10 \%$ neutral buffered formalin to be used for placental malaria histopathology.

\section{Malaria status}

Thick blood films were air-dried and Field's stained. Plasmodium falciparum malaria parasitaemia per $\mu \mathrm{l}$ was determined by counting parasites per 200 leukocytes, assuming 6000 leukocytes per $\mu$ l [29]. Placental malaria histopathology was determined by SJR as described [13]; stage of infection and degree of malaria pigment in placental monocytes and fibrin were evaluated to determine disease severity [13]. For the purposes of data analysis, malaria infection was defined as either maternal (any parasites on maternal peripheral thick blood film) or placental (any parasites on placental thick blood film or histopathology).

\section{HIV status}

All subjects were consented and received HIV pre-test and post-test counseling before the onset of active labor. HIV status was determined by Serocard rapid test for HIV-1 and 2 (Trinity Biotech, Wicklow, Ireland) and Determine HIV1/2 (Abbott Diagnostics, Abbott Park, Illinois, USA); disagreement between tests was settled by HIV-SPOT ELISA (Genelabs Diagnostics, Singapore).

\section{Markers of haematological status}

Haemoglobin $(\mathrm{Hb})$ concentration were measured in peripheral and cord blood samples using a Hemocue $e^{\circledast}$ haemoglobinometer (HemoCue $\mathrm{AB}$, Ängelholm, Sweden); some results were not available as samples clotted. Maternal peripheral and cord plasma soluble transferrin receptor (sTfR) and ferritin were assayed by enzymelinked immunosorbent assay (ELISA) kits according to manufacturer's instructions (Ramco Laboratories, Stafford, TX; and IBL, Hamburg, Germany; respectively). Data were analysed in Microsoft Excel using a log-log standard curve. Limits of detection were as follows: $1 \mu \mathrm{g} / \mathrm{ml}$ (sTfR) and $0.59 \mathrm{ng} / \mathrm{ml}$ (ferritin).

\section{Markers of inflammation}

Maternal peripheral, placental and cord plasma tumor necrosis factor- $\alpha$ (TNF- $\alpha$ ) and transforming growth factor$\beta$ (TGF- $\beta$ ) and maternal peripheral and cord plasma C reactive protein (CRP) levels were also assayed by ELISA (R\&D Systems, Minneapolis, MN, USA). Color was developed by SigmaFast o-phenylenediamine dihydrochloride tablets (Sigma, St. Louis, MO, USA). Data were analysed as described above. Limits of detection were as follows: 4 $\mathrm{pg} / \mathrm{ml}(\mathrm{TNF}-\alpha), 13 \mathrm{pg} / \mathrm{ml}$ (TGF- $\beta$ ), and $1 \mu \mathrm{g} / \mathrm{ml}$ (CRP).

\section{Markers of chronic foetal hypoxia}

Because scalp blood gas analysis, the most accurate means of assessing foetal hypoxia, was not feasible in the study setting, other proxies for chronic foetal hypoxia were measured: erythropoietin (Epo) [19], and cortisol and corticotrophin-releasing hormone (CRH) [20]. Maternal peripheral, placental, and cord plasma erythropoietin (Epo) levels were assayed by ELISA according to manufacturer's instructions (IBL, Hamburg, Germany). Placental and cord cortisol (CRT) and placental CRH were determined by ELISA as well (cortisol: R\&D Systems, Minneapolis, MN, USA; CRH: Phoenix Pharmaceuticals, Belmont, CA, USA, respectively). Data were analysed as described above. Limits of detection were as follows: $0.4 \mathrm{mU} / \mathrm{mL}$ (EPO), $0.16 \mathrm{ng} / \mathrm{ml}$ (cortisol), and $0.19 \mathrm{ng} / \mathrm{ml}(\mathrm{CRH})$.

\section{Ethical approval}

This study was approved by the College of Medicine Research Committee, University of Malawi, and the Institutional Review Boards of the University of Michigan and the University of North Carolina.

\section{Statistical analyses}

Data were entered in MS-Access and analyses were performed using SPSS v.10 and Intercooled Stata 8.0. Skewed data were $\log$ or $(\log +1)$ transformed before certain analyses. Maternal characteristics in malaria-infected and uninfected women (Table 2) were compared by t-tests (continuous variables) and chi-squared tests (dichotomous variables). Mann-Whitney U tests were used to compare maternal and cord characteristics in malaria-infected and uninfected women (Tables 3 and 4). Bonferroni's method was used as a more conservative measure of significance for multiple comparisons [30]; $\mathrm{p}$ values reported reflect pre-adjustment values. The 5\% significance level was used to determine significance. 
Table I: Malaria infections by compartment and diagnostic method

\begin{tabular}{|c|c|c|c|c|c|}
\hline Malaria infection in any compartment & & Compartment & $\begin{array}{l}\text { Total } \\
\text { cases }\end{array}$ & Placental diagnostic method (\# positive cases) & $\begin{array}{l}\text { Total } \\
\text { cases }\end{array}$ \\
\hline \multirow[t]{7}{*}{ Present } & 42 & Maternal malaria only & 10 & & \\
\hline & & Maternal and placental malaria & 19 & Thick smear & 1 \\
\hline & & & & Histopathology & 5 \\
\hline & & & & Both & 13 \\
\hline & & Placental malaria only & 13 & Thick smear & 0 \\
\hline & & & & Histopathology & 4 \\
\hline & & & & Both & 9 \\
\hline Absent & 48 & & & & \\
\hline Total & 90 & & & & \\
\hline
\end{tabular}

Table 2: Maternal characteristics in women with and without maternal peripheral malaria infection

\begin{tabular}{|c|c|c|c|}
\hline & $\begin{array}{l}\text { Malaria-infected mean } \pm \text { STD }(n) \\
\text { total } n: 29\end{array}$ & $\begin{array}{l}\text { Malaria-uninfected mean } \pm \text { STD }(n) \\
\text { total } n: 61\end{array}$ & \\
\hline Age & $20.9 \pm 3.2(29)$ & $22.8 \pm 5.2(6 \mathrm{I})$ & $t=2.11, p=0.038$ \\
\hline Parity & $1.5 \pm 0.9(29)$ & $2.1 \pm 1.5(6 \mathrm{I})$ & $t=2.26, p=0.026$ \\
\hline Number of antenatal clinic visits & $4.7 \pm 2.0(29)$ & $5.6 \pm 2.3(61)$ & $\mathrm{t}=1.78, p=0.079$ \\
\hline Maternal weight $(\mathrm{kg})$ & $56.4 \pm 8.4(29)$ & $59.0 \pm 7.4(61)$ & $t=1.51, p=0.136$ \\
\hline Maternal height $(\mathrm{cm})$ & $154.6 \pm 6.0(29)$ & $155.3 \pm 4.9(6 \mid)$ & $t=0.60, p=0.552$ \\
\hline BMI & $23.6 \pm 2.9(29)$ & $24.4 \pm 2.6(61)$ & $t=1.44, p=0.153$ \\
\hline $\operatorname{MUAC}(\mathrm{cm})$ & $23.7 \pm 2.9(16)$ & $24.6 \pm 2.2(38)$ & $\mathrm{t}=1.33, \mathrm{p}=0.190$ \\
\hline Took iron supplements & $86 \%(25 / 29)$ & $93 \%(55 / 59)$ & $\chi^{2}=1.16, p=0.282$ \\
\hline Took antimalarial tablets & $83 \%(24 / 29)$ & $95 \%(55 / 58)$ & $\chi^{2}=3.37, p=0.066$ \\
\hline Slept under mosquito net & $17 \%(5 / 29)$ & $31 \%(18 / 58)$ & $\chi^{2}=1.89, p=0.169$ \\
\hline $8^{\text {th }}$ grade education or less & $48 \%(14 / 29)$ & $52 \%(32 / 61)$ & $\chi^{2}=0.14, p=0.711$ \\
\hline Lived in a mud-walled house & $77 \%(20 / 26)$ & $69 \%(35 / 5 I)$ & $\chi^{2}=0.58, p=0.446$ \\
\hline Mother self or formally employed & $21 \%(6 / 29)$ & $20 \%(12 / 61)$ & $\chi^{2}=0.01, p=0.910$ \\
\hline Father self or formally employed & $92 \%(23 / 25)$ & $86 \%(44 / 51)$ & $\chi^{2}=0.53, p=0.468$ \\
\hline
\end{tabular}

\section{Results}

\section{Study population}

Of the 90 study participants, 29 had maternal peripheral malaria infections, 32 had placental malaria infections, and 42 had infections in one or both compartments. No cord blood malaria was identified in this study. Table 1 cross-references malaria infections by compartment and diagnostic method.

Table 2 shows the characteristics of study enrollees classified by maternal peripheral malaria. All women were HIV negative. Women with and without peripheral malaria infections were similar in terms of age and anthropometric measures. However, malaria-infected women were younger, of lower parity, and tended to have fewer antenatal clinic visits (Table 2). Socioeconomic status, as measured by educational level, house construction, and employment status, did not differ between the groups (Table 2). When women were alternatively classified by placental malaria status, there were again no significant differences in study participant characteristics (data not shown). However, when reclassified according to malaria infection in any compartment (maternal and/or placental), malaria-infected women had significantly lower BMI $(23.4 \pm 4.0$ vs. $24.8 \pm 2.4 ; \mathrm{p}=0.02)$ and fewer antenatal clinic visits $(4.8 \pm 1.8$ vs. $5.7 \pm 2.5 ; \mathrm{p}=0.045)$; no other characteristics differed between the groups (data not shown).

Data on the effects of malaria on maternal and foetal markers of haematological status, inflammation, and chronic hypoxia are presented in two tables: Table 3 presents the effects of maternal peripheral malaria on the markers, and Table 4 presents the effects of placental malaria. 
Table 3: Mann-Whitney $U$ test of effect of maternal peripheral malaria on maternal and neonatal haematological and inflammatory status

\begin{tabular}{|c|c|c|c|}
\hline & Infected median (IQRa) n (total n: 29) & Uninfected median (IQR) n (total n: 6I) & $\mathbf{p}$ \\
\hline \multicolumn{4}{|l|}{ Maternal } \\
\hline $\mathrm{Hb}(\mathrm{g} / \mathrm{dL})$ & $10.8(10.1-11.2) 29$ & $12.1(11.1-13.1) 61$ & $<0.00 \mathrm{I}^{\mathrm{b}}$ \\
\hline $\mathrm{sTfR}(\mu \mathrm{g} / \mathrm{ml})$ & $5.7(3.8-9.2) 29$ & $6.6(4.9-9.7) 6 I$ & 0.460 \\
\hline ferritin (ng/ml) & $95.3(42.3-180.8) 29$ & $16.5(6.0-33.1) 61$ & $0.00 I^{b}$ \\
\hline TNF- $\alpha(\mathrm{pg} / \mathrm{ml})$ & $22.9(7.9-72.1) 29$ & $1.8(0.0-24.4) 61$ & $0.00 I^{b}$ \\
\hline TGF- $\beta$ (ng/ml) & $11.0(6.0-15.9) 29$ & $15.5(9.6-18.3) 55$ & 0.027 \\
\hline $\operatorname{CRP}(\mu \mathrm{g} / \mathrm{ml})$ & $85.0(59.2-195.4) 29$ & $7.6(2.8-26.2) 61$ & $<0.00 I^{b}$ \\
\hline Epo (mU/L) & $60.6(41.0-98.5) 29$ & $32.7(21.6-52.6) 61$ & $0.00 I^{b}$ \\
\hline \multicolumn{4}{|l|}{ Cord } \\
\hline $\mathrm{Hb}(\mathrm{g} / \mathrm{dL})$ & $15.9(14.5-16.9) 22$ & $15.6(\mid 4.5-17.1) 48$ & 0.849 \\
\hline $\operatorname{sTfR}(\mu \mathrm{g} / \mathrm{ml})$ & $6.7(4.8-9.9) 29$ & $7.8(4.9-9.7) 60$ & 0.430 \\
\hline ferritin (ng/ml) & $135.5(66.7-276.3) 29$ & $99.0(39.4-158.7) 60$ & 0.040 \\
\hline TNF- $\alpha(\mathrm{pg} / \mathrm{ml})$ & $1.0(0.0-8.4) 28$ & $2.7(0.0-16.6) 59$ & $0.37 \mid$ \\
\hline TGF- $\beta$ (ng/ml) & $17.8(13.5-24.0) / 5$ & $27.7(20.7-31.9) 32$ & 0.019 \\
\hline CRP $(\mu \mathrm{g} / \mathrm{ml})$ & $1.5(0.7-1.7) 28$ & $1.0(0.0-1.6) 61$ & 0.169 \\
\hline Epo (mU/L) & $27.1(13.4-58.9) 29$ & $25.8(\mid 2.5-39.1) 61$ & $0.64 I$ \\
\hline
\end{tabular}

aQR: Inter-quartile range

b Significant after Bonferroni's adjustment for multiple comparisons.

Table 4: Mann-Whitney $U$ test of effect of placental malaria on markers of neonatal haematological, inflammatory, and hypoxic status

\begin{tabular}{|c|c|c|c|}
\hline & Infected median (IQR ${ }^{a}$ ) (total n: 32) & Uninfected median (IQR) n (total n: 58) & \\
\hline \multicolumn{4}{|l|}{ Cord } \\
\hline $\mathrm{Hb}(\mathrm{g} / \mathrm{dL})$ & $15.4(13.7-16.8) 25$ & $16.0(15.0-17.1) 45$ & $p=0.128$ \\
\hline $\mathrm{sTfR}(\mu \mathrm{g} / \mathrm{ml})$ & $6.7(5.1-9.9) 32$ & $7.7(4.3-9.6) 58$ & $P=0.765$ \\
\hline ferritin (ng/ml) & $129.0(61.9-248.6) 32$ & $101.0(41.2-210.8) 57$ & $p=0.184$ \\
\hline TNF- $\alpha$ (pg/ml) & $1.7(0.0-5.6) 30$ & $2.7(0.0-15.9) 57$ & $p=0.552$ \\
\hline TGF- $\beta$ (ng/ml) & $19.5(15.6-30.3) 16$ & $26.8(\mid 7.9-31.8) 31$ & $p=0.080$ \\
\hline $\operatorname{CRP}(\mu \mathrm{g} / \mathrm{ml})$ & $1.5(0.7-1.6) 31$ & $1.0(0.0-1.6) 58$ & $p=0.289$ \\
\hline Epo $(m U / L)$ & $25.4(13.4-58.1) 32$ & $27.5(12.5-45.1) 58$ & $p=0.940$ \\
\hline Cortisol $(\mu \mathrm{g} / \mathrm{ml})$ & $421.0(283.5-538.5) 32$ & $511.0(324.0-677.5) 53$ & $p=0.425$ \\
\hline \multicolumn{4}{|l|}{ Placenta } \\
\hline Cortisol $(\mu \mathrm{g} / \mathrm{ml})$ & $191.0(155.5-251.0) 29$ & $172.0(132.0-248.5) 53$ & $p=0.357$ \\
\hline $\mathrm{CRH}(\mathrm{pg} / \mathrm{ml})$ & $90.0(42.5-126.4) 24$ & $72.3(41.5-116.3) 43$ & $p=0.421$ \\
\hline
\end{tabular}

aIQR: Inter-quartile range

The effect of malaria on haematological status differed markedly between women and neonates. Compared to their uninfected counterparts, women characterized by any of the three definitions of malaria infection tended to have significantly lower maternal $\mathrm{Hb}$ concentrations (maternal: Table 3; placental: $\mathrm{p}=0.017$; any: $\mathrm{p}<0.001$ ). Unlike maternal haematological status, neonatal characteristics were protected from the effects of maternal and placental malaria. Mean cord $\mathrm{Hb}$ levels did not differ between malaria-infected and uninfected women (Tables 3 and 4). In addition, malarial disease severity, including peripheral and placental parasite density, stage of disease, and deposition of fibrin and malaria pigment in placental monocytes, had no effect on neonatal $\mathrm{Hb}$ (data not shown). Neither cord nor maternal sTfR levels were affected by malaria infection in this study (Tables 3 and 4).

Markers of inflammation were also altered in malariainfected women, who had significantly elevated CRP and TNF- $\alpha$ (maternal: Table 3; placental: CRP ( $\mathrm{p}<0.001)$, TNF- $\alpha(\mathrm{p}=0.022)$; any: CRP $(\mathrm{p}<0.001)$, TNF- $\alpha(\mathrm{p}=$ $0.004)$ ) and lower TGF- $\beta$, although this result was not significant after Bonferroni's adjustment (maternal: Table 3; placental: NS; any: $p=0.010)$. There was no effect of maternal malaria on foetal TNF- $\alpha$ or CRP (Table 3). TGF$\beta$ was significantly decreased in the cord blood of neonates with peripheral malaria-infected mothers, 
although this result was not significant after Bonferroni's adjustment (Table 3). Among babies of malaria-infected women, neither increased maternal or placental parasite density nor markers of disease severity were associated with increases in measures of neonatal inflammation (data not shown). However, elevated maternal CRP in women with peripheral malaria infections was associated with significantly increased cord CRP $(r=0.48, \mathrm{p}=0.010)$ and decreased cord TGF- $\beta(r=-0.60, p=0.019)$, suggesting an association between maternal and foetal immune activation.

Malaria-infected women had significantly higher ferritin levels than uninfected women (maternal: Table 3; placental: $\mathrm{p}<0.001$; any: $\mathrm{p}<0.001$ ). Cord ferritin was significantly increased in the cord blood of neonates with peripheral malaria-infected mothers, although this result was not significant after Bonferroni's adjustment (Table 2). In addition, cord ferritin was correlated with increasing maternal parasite load in malaria-infected women $(\mathrm{r}=$ $0.474, \mathrm{p}=0.009)$. The notion that ferritin levels in this group reflected malaria-related inflammation is further supported by the inverse correlation between cord ferritin and cord TGF- $\beta(\mathrm{r}=-.593, \mathrm{p}=0.020)$. Additionally, primigravids with placental malaria infections, who tend to experience its inflammatory effects more acutely than multigravids, had significantly higher cord ferritin levels than did multigravid malaria-infected women $(\mathrm{p}=$ $0.021)$. However, despite the indications of immune activation in neonates of malaria-infected women, none of the cord immune markers were correlated with cord $\mathrm{Hb}$ or sTfR (data not shown).

Although women characterized by any of the three definitions of malaria infection tended to have significantly higher Epo levels than uninfected women (maternal: Table 3; placental: NS; any: $\mathrm{p}=0.004$ ), none of the proxies for foetal hypoxia examined in the study (cord Epo, placental and cord cortisol, and placental CRH) were increased in the neonates of malaria-infected women (Tables 3 and 4). Among malaria-infected women, increased maternal and placental parasitaemia and markers of disease severity were also not associated with increased levels of these factors (data not shown).

Neonatal haematological, immune and hypoxic markers were then examined in relation to poor birth outcomes that have been associated with maternal malaria, particularly low birthweight and preterm delivery. In this study, neither the presence nor the severity of maternal or placental malaria was associated with decreased birthweight or gestational age, perhaps due to the limited sample size (data not shown). Unsurprisingly, therefore, neither decreased maternal nor cord Hb was significantly associated with poorer birth outcomes in malaria-infected women (data not shown), although cord sTfR levels, which were not different between neonates of malariainfected and uninfected women (Tables 3 and 4), were inversely associated with birthweight in women with maternal, but not placental, malaria $(\mathrm{r}=-.452, \mathrm{p}=0.014)$. In neonates of women with both maternal and placental malaria, elevated cord ferritin was correlated with lower birthweights (maternal: $\mathrm{r}=-0.427, \mathrm{p}=0.021$; placental: $\mathrm{r}$ $=-0.374, p=0.035)$, and in those of women with maternal malaria, with shorter gestations as well $(\mathrm{r}=-0.432$, $\mathrm{p}$ $=0.024)$. This association was not due to inflammation alone, since there was no association with cord CRP or TGF- $\beta$, nor to foetal haematopoiesis alone, since there was no association with cord Epo (data not shown). However, the data suggest that a combination of the haematological and inflammatory processes might be associated with poor birth outcomes commonly found following malaria infection during pregnancy.

\section{Discussion}

In this study, the haematological status of neonates of mothers with malaria parasitaemia at delivery was not significantly impacted. Despite the effect of malaria on maternal $\mathrm{Hb}$, which was expectedly lower, neonatal $\mathrm{Hb}$ levels were not decreased in the cord blood of malariainfected compared to uninfected women. In addition, cord $\mathrm{Hb}$ values were not correlated to maternal $\mathrm{Hb}$ concentration in either group or severity of malaria, as described in the Results section. Although the sample size was relatively small, these results resemble more closely the results from Western studies, which tend to find unaffected cord values, than the studies of malaria- and nonmalaria-exposed mother-neonate pairs in developing countries, as reviewed by Brabin [4]. It is unclear why, but the high cord haemoglobin levels observed in this study may relate to the high rates of antimalarial usage and iron supplementation in Malawian women (Table 2), which might provide a protective effect. The maintenance of cord $\mathrm{Hb}$ levels despite the presence of maternal anaemia and malaria suggests that the foetus has developed mechanisms to preferentially obtain sufficient iron and produce adequate amounts of red cells. Iron is transported unidirectionally from mother to foetus across a concentration gradient [31], and thus stores should be preferentially preserved in the foetus.

Ferritin is an iron storage protein that is an acute phase reactant in the presence of infection. While cord ferritin decreases in foetuses of anaemic mothers without malaria, it appears to increase in foetuses of mothers with increasing parasitaemia. Increased ferritin in the presence of inflammation has been suggested to reflect an evolutionary strategy by which the body removes bioavailable iron from the presence of parasites [32]. In foetuses of mothers with malaria, it may have an additional function: 
to help sequester iron obtained from the mother. Interestingly, in this study, elevated cord ferritin levels best predicted poor birth outcomes, including shorter gestation and lower birth weight. It is unclear why this association was found, particularly since no association was found in this study between birth outcomes and malaria infection or maternal anaemia, two well-established risk factors. This suggests that increased cord ferritin might be a result of the same foetal stresses that cause poor birth outcomes.

Many researchers have assumed that foetal hypoxia, rather than inflammation, mediates the effect of malaria and maternal anaemia on birth outcomes, particularly low birth weight. Despite the induction of foetal hypoxia by maternal anaemia [20,33] and the decrease in umbilical blood flow in pregnant women with malaria [34], it has not been rigorously demonstrated that chronic low-grade hypoxia causes poor birth outcomes, and it is unclear how severe anaemia must be to induce foetal hypoxia. Foetal hypoxia is difficult to quantify in nonwestern settings. In developed countries, blood gases are collected as soon as the foetal scalp is discernable exiting the birth canal. This technique is not feasible in hospitals in developing countries, but several biochemical measures in cord blood may offer proxies for foetal hypoxia. In particular, Epo, the hormone primarily responsible for regulation of erythropoiesis, is stimulated by both anaemia and hypoxia [35] and is a good marker of chronic foetal hypoxia $[19,36]$ because Epo does not cross the placenta. Several studies have reported both adequate [37-39] and inadequate $[40,41]$ Epo production for the level of anaemia in malaria-infected children and adults, and this question requires further investigation. In this study, maternal Epo was elevated in malaria-infected women (Table 3), but cord Epo levels were not affected by either maternal or placental malaria infections (Tables 3 and 4).

Allen [20] hypothesized that foetal stress hormones (cortisol and CRH) might mediate the link between maternal anaemia and poor birth outcomes, via the effect of anaemia-induced foetal hypoxia on these hormones. In this study, cord cortisol and placental cortisol and CRH were neither elevated in association with maternal malaria infection nor associated with poor birth outcomes. This may reflect the inadequacy of these factors as markers for chronic foetal hypoxia, either in general or in cord blood, or may simply be a result of the small sample size. On the other hand, hypoxia in the foetus may be so fleeting, as the foetus downregulates its growth in relation to available oxygen levels, that it does not trigger lasting detectable markers. This response is seen in sheep, where pregnant females with experimentally-induced anaemia evince a compensatory decrease in foetal growth but no actual evidence of hypoxia [42].

\section{Conclusion}

In summary, cord haemoglobin levels were unchanged by maternal malaria and anaemia during pregnancy in this population. However, maternal parasitaemia induced a foetal inflammatory response, specifically lower TGF- $\beta$ and higher ferritin levels. Elevated cord ferritin in turn was associated with lower birthweights and shorter gestations.

\section{Authors' contributions}

ETA was responsible for conception and design of the study; IRB approval; conducting assays; analysis and interpretation of data; drafting the paper; and revising it for publication. JK and DDK performed many of the assays and analyses of these assays. VM designed the larger study and conducted much of the data analysis of that study that formed the foundation of this one. ET and VLM supervised patient enrollment and acquisition of data and aided in its submission to the IRB. MEM and SRM were central to the conception and design of the study, the analysis and interpretation of data, and the revision of the paper for publication. SRM was involved in the conception and design of the study; IRB approval; analysis and interpretation of data; drafting the paper; and revising the paper for publication.

\section{Acknowledgements}

Funding for this study was provided by The Wenner-Gren Foundation for Anthropological Research (ETA), the Anthropology Department of the University of Michigan (ETA), the Rackham School of Graduate Studies at the University of Michigan (ETA), the Wellcome Trust Career Development Fellowship (SJR; ref 0460 I2), and the NIH (SRM; Al 49084).

\section{References}

I. Brabin Bj: An analysis of malaria in pregnancy in Africa. Bull World Health Organ 1983, 61:1005-1016.

2. Menendez C, Ordi J, Ismail MR, Ventura PJ, Aponte JJ, Kahigwa E, Font F, Alonso PL: The impact of placental malaria on gestational age and birth weight. J Infect Dis 2000, 18 I:1740-1745.

3. Menendez C, Fleming AF, Alonso PL: Malaria-related anaemia. Parasitol Today 2000, 16:469-476.

4. Brabin B: Foetal anaemia in malarious areas: its causes and significance. Ann Trop Paediatr 1992, 12:303-310.

5. Erdem A, Erdem M, Arslan M, Yazici G, Eskandari R, Himmetoglu O: The effect of maternal anaemia and iron deficiency on fetal erythropoiesis: comparison between serum erythropoietin, haemoglobin and ferritin levels in mothers and newborns. J Matern Fetal Neonatal Med 2002, I I :329-332.

6. Hokama T, Takenaka S, Hirayama K, Yara A, Yoshida K, Itokazu K, Kinjho R, Yabu E: Iron status of newborns born to iron deficient anaemic mothers. J Trop Pediatr 1996, 42:75-77.

7. Agarwal KN, Krishna M, Singla PN, Jain A: Effects of hematinic and protein supplementation on the feto-placental unit in maternal anaemia. Indian Pediatr 1984, 21:765-771.

8. Tracer DP: Reproductive and socio-economic correlates of maternal haemoglobin levels in a rural area of Papua New Guinea. Trop Med Int Health 1997, 2:5 I3-518.

9. Bhargava M, lyer PU, Kumar R, Ramji S, Kapani V, Bhargava SK: Relationship of maternal serum ferritin with foetal serum ferritin, birth weight and gestation. J Trop Pediatr I99I, 37:|49-I52.

10. Ballew C, Haas JD: Haematologic evidence of foetal hypoxia among newborn infants at high altitude in Bolivia. Am J Obstet Gynecol 1986, 155:166-169.

II. Abdalla SH: Haematopoiesis in human malaria. Blood Cells 1990, 16:401-416. discussion 4I7-409 
12. Huddle JM, Gibson RS, Cullinan TR: The impact of malarial infection and diet on the anaemia status of rural pregnant Malawian women. Eur J Clin Nutr 1999, 53:792-80I.

13. Rogerson SJ, Pollina E, Getachew A, Tadesse E, Lema VM, Molyneux ME: Placental monocyte infiltrates in response to Plasmodium falciparum malaria infection and their association with adverse pregnancy outcomes. Am J Trop Med Hyg 2003, 68: $115-119$.

14. Fried M, Muga RO, Misore AO, Duffy PE: Malaria elicits type I cytokines in the human placenta: IFN-gamma and TNFalpha associated with pregnancy outcomes. J Immunol 1998, 1 60:2523-2530.

15. Rogerson SJ, Brown HC, Pollina E, Abrams ET, Tadesse E, Lema VM Molyneux ME: Placental tumor necrosis factor alpha but not gamma interferon is associated with placental malaria and low birth weight in Malawian women. Infect Immun 2003, 71:267-270

16. Moormann AM, Sullivan AD, Rochford RA, Chensue SW, Bock PJ Nyirenda T, Meshnick SR: Malaria and pregnancy: placental cytokine expression and its relationship to intrauterine growth retardation. J Infect Dis 1999, 180:1987-1993.

17. Fievet N, Ringwald P, Bickii J, Dubois B, Maubert B, Le Hesran JY, Cot $M$, Deloron $\mathrm{P}$ : Malaria cellular immune responses in neonates from Cameroon. Parasite Immunol 1996, I 8:483-490.

18. King CL, Malhotra I, Wamachi A, Kioko J, Mungai P, Wahab SA, Koech D, Zimmerman P, Ouma J, Kazura JW: Acquired immune responses to Plasmodium falciparum merozoite surface protein-I in the human foetus. J Immunol 2002, I 68:356-364.

19. Buescher U, Hertwig K, Wolf C, Dudenhausen JW: Erythropoietin in amniotic fluid as a marker of chronic foetal hypoxia. Int J Gynaecol Obstet 1998, 60:257-263.

20. Allen LH: Biological mechanisms that might underlie iron's effects on foetal growth and preterm birth. J Nutr 200I, | 3 |:58IS-589S.

21. Pacifici GM, Nottoli R: Placental transfer of drugs administered to the mother. Clin Pharmacokinet 1995, 28:235-269.

22. Zanjani ED, Pixley JS, Slotnick N, MacKintosh FR, Ekhterae D, Clemons G: Erythropoietin does not cross the placenta into the foetus. Pathobiology 1993, 61:21 I-2I5.

23. Starreveld JS, Kroos MJ, Van Suijlen JD, Verrijt CE, Van Eijk HG, Van Dijk JP: Ferritin in cultured human cytotrophoblasts: synthesis and subunit distribution. Placenta 1995, 1 6:383-395.

24. Zaretsky MV, Alexander JM, Byrd W, Bawdon RE: Transfer of inflammatory cytokines across the placenta. Obstet Gynecol 2004, 103:546-550.

25. Gutteberg TJ, Askvik K, Jorgensen T: Serum lactoferrin and Creactive protein in mother and newborn after preterm rupture of membranes. Acta Obstet Gynecol Scand 1986, 65:203-205.

26. Yang K: Placental II beta-hydroxysteroid dehydrogenase: barrier to maternal glucocorticoids. Rev Reprod 1997, 2:129-132.

27. Mwapasa V, Rogerson SJ, Molyneux ME, Abrams ET, Kamwendo DD, Lema VM, Tadesse E, Chaluluka E, Wilson PE, Meshnick SR: The effect of Plasmodium falciparum malaria on peripheral and placental HIV-I RNA concentrations in pregnant Malawian women. Aids 2004, I 8: I05 I-1059.

28. Ballard JL, Khoury KC, Wedig K, Wang L, Eilers-Walsman BL, Lipp R: New Ballard Score, expanded to include extremely premature infants. J Pediatr 1991, I | 9:4 I 7-423.

29. Rogerson SJ, Chaluluka E, Kanjala M, Mkundika P, Mhango C, Molyneux ME: Intermittent sulfadoxine-pyrimethamine in pregnancy: effectiveness against malaria morbidity in Blantyre, Malawi, in 1997-99. Trans R Soc Trop Med Hyg 2000, 94:549-553.

30. Sokal RR, Rohlf FJ: Biometry New York: W. H. Freeman and Company; 1995.

31. Fletcher J, Suter PE: The transport of iron by the human placenta. Clin Sci 1969, 36:209-220.

32. Weinberg ED: Nutritional immunity. Host's attempt to withold iron from microbial invaders. Jama I975, 23 I:39-4I.

33. Rondo PH, Tomkins AM: Maternal iron status and intrauterine growth retardation. Trans $R$ Soc Trop Med Hyg 1999, 93:423-426.

34. Arbeille P, Carles G, Bousquet F, Body G, Lansac J: Foetal cerebra and umbilical artery blood flow changes during pregnancy complicated by malaria. J Ultrasound Med 1998, 1 7:223-229.
35. Vora M, Gruslin A: Erythropoietin in obstetrics. Obstet Gynecol Surv 1998, 53:500-508

36. Ostlund E, Lindholm H, Hemsen A, Fried G: Foetal erythropoietin and endothelin-I: relation to hypoxia and intrauterine growth retardation. Acta Obstet Gynecol Scand 2000, 79:276-282.

37. Burchard GD, Radloff P, Philipps J, Nkeyi M, Knobloch J, Kremsner PG: Increased erythropoietin production in children with severe malarial anaemia. Am J Trop Med Hyg 1995, 53:547-55I.

38. Nussenblatt V, Mukasa G, Metzger A, Ndeezi G, Garrett E, Semba RD: Anaemia and interleukin-10, tumor necrosis factor alpha, and erythropoietin levels among children with acute, uncomplicated Plasmodium falciparum malaria. Clin Diagn Lab Immunol 200I, 8: I I64-I I70.

39. Verhoef H, West CE, Kraaijenhagen R, Nzyuko SM, King R, Mbandi MM, van Laatum S, Hogervorst R, Schep C, Kok FJ: Malarial anaemia leads to adequately increased erythropoiesis in asymptomatic Kenyan children. Blood 2002, I 00:3489-3494.

40. el Hassan AM, Saeed AM, Fandrey J, Jelkmann W: Decreased erythropoietin response in Plasmodium falciparum malaria-associated anaemia. Eur J Haematol 1997, 59:299-304.

4I. Vedovato M, De Paoli Vitali E, Dapporto M, Salvatorelli G: Defective erythropoietin production in the anaemia of malaria. Nephrol Dial Transplant 1999, I 4: 1043-1044.

42. Mostello D, Chalk C, Khoury J, Mack CE, Siddiqi TA, Clark KE: Chronic anaemia in pregnant ewes: maternal and foetal effects. Am J Physiol 1991, 26 I:R I075-I083.
Publish with Biomed Central and every scientist can read your work free of charge

"BioMed Central will be the most significant development for disseminating the results of biomedical research in our lifetime. "

Sir Paul Nurse, Cancer Research UK

Your research papers will be:

- available free of charge to the entire biomedical community

- peer reviewed and published immediately upon acceptance

- cited in PubMed and archived on PubMed Central

- yours - you keep the copyright
BioMedcentral 